\title{
Effects of ground freezing and snow avalanche deposits on debris flows in alpine environments
}

\author{
E. Bardou ${ }^{1}$ and R. Delaloye ${ }^{2}$ \\ ${ }^{1}$ Quanterra, Ch. de la Tour Grise 28, 1007 Lausanne, Switzerland \\ ${ }^{2}$ Department of Geosciences, Geography, University of Fribourg, Switzerland
}

Received: 8 April 2004 - Revised: 3 September 2004 - Accepted: 13 September 2004 - Published: 22 September 2004

Part of Special Issue "Monitoring and modeling of landslides and debris flows"

\begin{abstract}
Debris flows consist of a mixture of water and sediments of various sizes. Apart from few exceptions, the water is usually contributed directly from precipitation. In a high mountain environment like the Alps, it appears necessary to consider infiltration of water into the ground during rainfall events, the runoff characteristics and the potential supply of sediment as a function of a multitude of climatic and hydrogeological factors. This paper outlines several new processes - either linked to ice formation in the ground before an event, or to the presence of snow avalanche deposits - that change the probability of observing an event.
\end{abstract}

These processes were identified during field observations connected with extreme weather events that occurred recently in the Valais Alps (south-western Switzerland): they can be seen as factors either amplifying or reducing the potential of slope instability caused by the precipitation event. An intense freezing of the ground during the week preceding the exceptional rainfall event in mid-October 2000 amplified the probability of triggering debris flows between roughly 1800 and $2300 \mathrm{~m}$ asl. Both growth of ice needles and superficial ground freezing destroyed soil aggregates (increasing the availability of sediments) and/or, a deeper ground freezing resulted in decreased infiltration rate (increased runoff) during the first hours of heavy rainfall. The presence of snow avalanche deposits in a gully could be simultaneously an amplifying factor (the snow deposits increase the base flow and create a sliding plane for the sediments, mainly at the time of summer storms) or a reducing factor (reduction in the impact energy of the raindrops, mainly at the time of winter storms) of the risk of triggering debris flows.

If it is not currently possible to establish rainfall threshold values for debris flow triggering, the knowledge and the implementation of these processes in the analysis of the potential triggering (for example by comparing the catchment hypsometric curve with the meteo-climatic situation) would nevertheless make the analysis of debris flows and forecasting more efficient.

Correspondence to: E. Bardou

(mail@quanterra.org)

\section{Introduction}

The complex processes which lead to the mobilization of a mixture of water and rocky materials of heterogeneous grainsizes in the form of a debris flow are very difficult to study in situ. From general point of view, two distinct mechanisms can occur during the initiation phase of a debris flow: the diffuse erosion within the catchment drainage network (also known as the runoff-dominated erosion) or localized liquefaction of an earth mass (also known as the infiltration triggered soil slip). These two mechanisms are not necessarily concomitant. In the case of diffuse erosion, our field observations coincide with those of other researchers (e.g. Meunier, 1991; Cannon et al., 2001) indicate that the paths left by debris flow sometimes gradually disappear with distance up the torrent gully. The exact initiation zone for the debris flow is then difficult to locate. This process is prevalent in areas impacted by forest fires (Cannon et al., 2001), but is also observed in alpine environment (e.g. Gostner et al., 2003). The mechanism of mobilization of an earth mass into a debris flow is described by several field studies (e.g. Ellen and Fleming, 1987; Jakob et al., 1997). In these cases, the mechanism is linked with the increase of the interstitial pore pressure. Laboratory experiments show that it is the rate of increase of the pore pressure that mainly influences the mobilization (Klubertanz et al., 2000). However, due to the difficulty in locating the potential failures before an event, only a few detailed studies have been successfully undertaken (e.g. Anderson and Sitar, 1995; Springman and Teysseire, 2001; Montgomery et al., 1997). Indeed, the precise mechanism leading to the initiation of debris flows still remain little studied in the field for a given event.

For both types of debris flow initiation processes, the supply of water is the principal driving factor. During a rainfall episode, both the moment and quantity of the water supply into the ground depend not only on the duration and intensity of the precipitation but also on hydrogeological factors on the elevation of the snowfall limit. Hungr et al. (1984) demonstrated the difficulty in envisaging the triggering of debris flows on the basis of rainfall alone, due to the extent that 


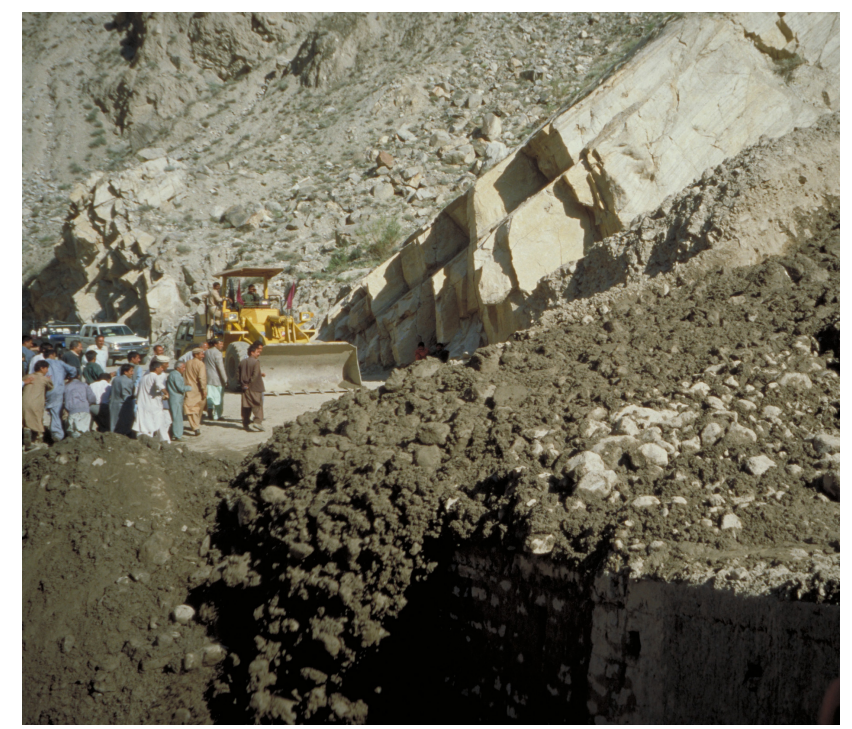

Fig. 1. Debris flow that occurred during sunny weather in June 1997 on the Karakoram Highway, Pakistan. This debris flow lasted approximately $2 \mathrm{~h}$ in the early afternoon and included several surges. The lack of rainfall allows us to suppose that this event was triggered by intense snowmelt.

hydrogeological variability can distort such analysis. Several studies undertaken in the Himalayan range also demonstrated that debris flows can be produced even without simultaneous rainfall (Wei and Gao, 1992; Jishan and Tianchi, 2001, author's observations, Fig. 1). In these cases, an intense snowmelt in the early summer that enhances both superficial and subsurface runoff provided the trigger for debris flow initiation. In glaciated mountain areas, the outburst of glacial or proglacial lakes, a hazard well known for instance in the Himalayan range (Mool et al., 2001), the Peruvian Andes (e.g. Reynolds, 1992), as well as, but more rarely, in the Alps (e.g. Haeberli et al., 2001; Huggel et al., 2003), is another mode for triggering debris flows not directly linked to rainfall. Other authors describe debris flow occurences in high mountain environments at a time when no rain was recorded (e.g. Zimmermann et al., 1997). Such events usually initiate from historical moraine deposits and could be related to the unusual behaviour of the glacial/proglacial hydrological system, but also, perhaps, to little known processes in permafrost areas (e.g. Lugon et al., 2000). Further huge rockwall/glacier collapses such as on Nevado Huascaràn, Peruvian Andes, in 1970 (Pfalker et al., 1971) or above Kolka Glacier (Caucasus) in 2002 (Kääb et al., 2003) or the sudden activity of a snow or ice covered volcano (Waitt et al., 1983; Fazel, 1991; Gomez et al., 2002) can be the cause of exceptional catastrophic events.

Since the end of the 1980's, several extreme rainfall events have affected the Central European Alps (CEA), most of them in late summer and autumn. The event analysis performed on these debris flows was based only on the rainfall and the temperature (Zimmermann, 1990; OFEE, 1991; Grebner, 1994; Tropeano et al., 2000; BWG, 2002). In these studies, temperature information defines only an altitudinal threshold for the transition between the solid and liquid phases of precipitation. However, apparent anomalies in debris-flow activity, for example magnitudes lower than those expected for an intense meteorological episode are recorded in one or the other of these events. This difference between observations and expected catchment behaviour motivated us to extend the usual "temperature-precipitationdebris flow triggering" field of investigation to consider the effects of other parameters such as previous ground freezing or snow avalanche deposits on debris-flow initiation area.

The goal of this paper is to describe observations from the Valais Alps, which permit the range of the parameters that lead and measurement to the triggering of debris flows in an alpine (often periglacial) environment during a rainfall episode to be enlarged. These observations should be seen as a first description of potential phenomena. Additional measurements should be undertaken before being able to estimate the thresholds usable for catchment monitoring and debris-flow activity/magnitude forecasting. Without calling into question the obvious relationship between precipitation and the triggering of debris flows, the new elements that are discussed in this paper will make a better analysis of the complex water, sediments and slope system possible, which will thereafter imply a better capacity to forecast such events. Three situations are described in the following. Each case begins with a description of the observations and then with the hypothesis which could explain the observations.

\section{Previous ground freezing on triggering debris flows}

During the extreme rainfall event which affected a large part of the CEA in October 2000, several watersheds presented unexpected sedimentary dynamics: torrents ${ }^{1}$ known to be prone to debris flows presented only a low intensity reaction (relatively scaled to the reported events) and others, considered less likely to produce significant debris flows, suffered flooding on the fan or in area where the section is restricted by bridges and where no obvious clues of such events are observable.

Some field observations and measurements during the week before the event suggest possible causes for the response of certain torrents. They do not claim to explain all the apparent anomalies in the initiation of debris flows during this climatic event, but indicate directions that might be followed for future analyse. The observations come from a number of different sites and allow complementary explanations to the analyses published by the governmental services concerning the relationship between precipitation and debris flows (BWG, 2002).

\footnotetext{
${ }^{1}$ In Europe, torrent is the term used for stream that develops in mountain area with a mean slope exceeding 6 to $10 \%$, with permanent discharge.
} 


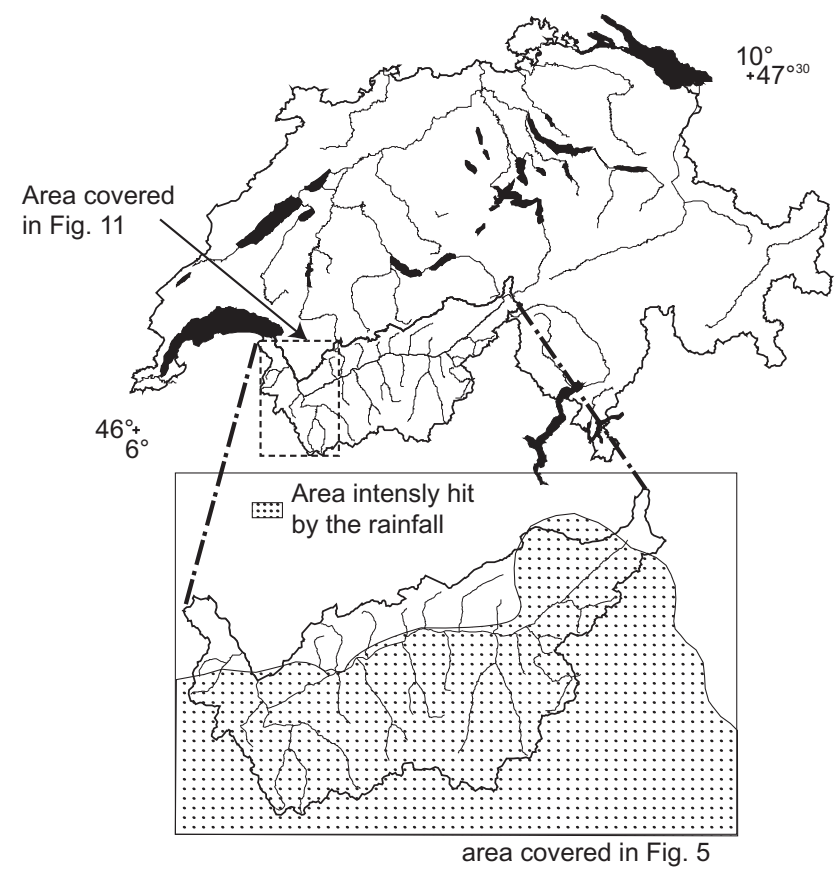

Fig. 2. The area most impacted by the extreme rainfall event of 2000 is shown black on the map. The detail depicts the Valais region, which is also used in the map in Fig. 4.

\subsection{Observations}

Exceptionally high quantities of precipitation were recorded between 13 and 17 October 2000 in most of the Valais Alps (BWG, 2002). Many catastrophic sedimentary events took place between 14 and 15 October, but not necessary in all torrents prone to debris-flow activity. An analysis of the meteorological conditions from the beginning of the month show that during the first week of October, mild weather was observed, with some precipitation and with the snow line varying between 2400 and $3000 \mathrm{~m}$ asl. A dramatic decrease in temperature took place from the afternoon of 6 October (cf. Fig. 4). The $0^{\circ} \mathrm{C}$ isotherm fell to about $1500 \mathrm{~m}$ asl. Then, the weather remained relatively cold until 12 October with new snowfalls above about $2200 \mathrm{~m}$ asl on 9 October. During the period between 7 and 12 October the mean air temperature was $-2^{\circ} \mathrm{C}$ at $2500 \mathrm{~m}$ asl at Lapires (western Valais Alps). At the same time, the mean $0^{\circ} \mathrm{C}$ isotherm laid at about $1900-2000 \mathrm{~m}$ asl (for instance, $-0.2^{\circ} \mathrm{C}$ on Moléson summit at $1972 \mathrm{~m}$ asl on northern side of the Alps; MeteoSwiss data). At the beginning of the extreme rainfall event on 13 October the snow line is estimated to have been at about 2200$2400 \mathrm{~m}$ asl (own observation). Above this elevation the snow cover reached $10-50 \mathrm{~cm}$ depth at that time.

At Lapires $(2500 \mathrm{~m}$ asl), positive air temperatures were recorded from the 12th in the afternoon (cf. Fig. 4). The maximum temperature $\left(+5^{\circ} \mathrm{C}\right)$ was observed on the 14 th in the morning and was followed by an increase in precipitation in this western part of the Valais Alps. Precipitation increased from $10 \mathrm{~mm} / 6 \mathrm{~h}$ in the morning of the 14 th to $\sim 25 \mathrm{~mm} / 6 \mathrm{~h}$

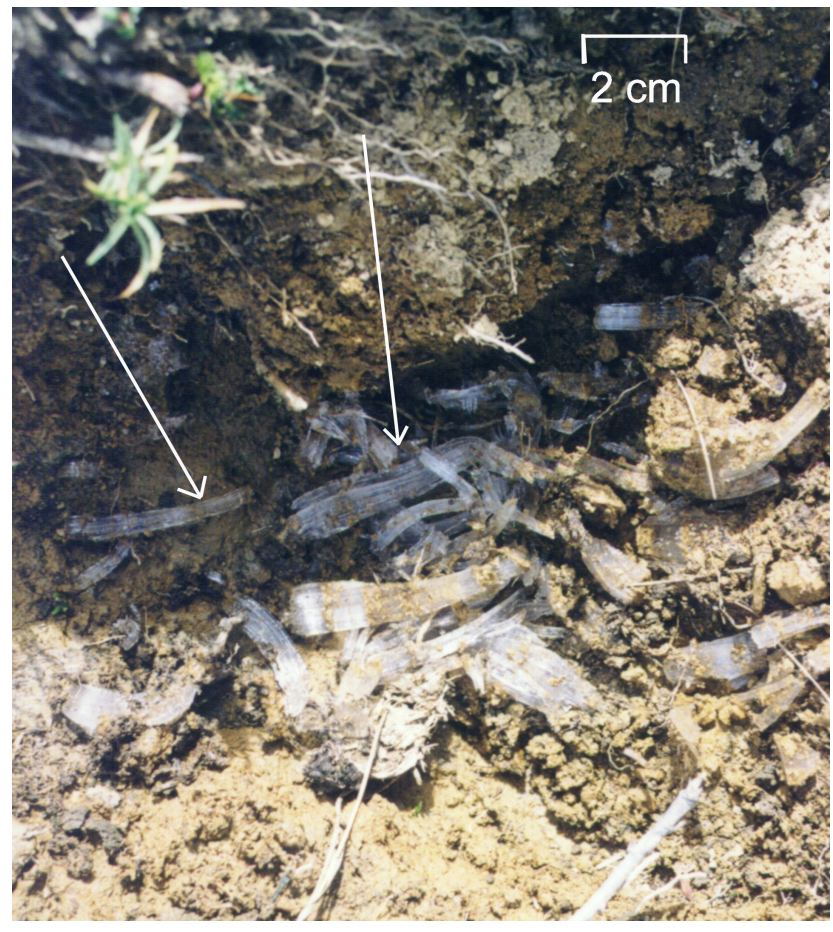

Fig. 3. Pipkrakes (ice needles) observed at $1800 \mathrm{~m}$ asl on 8 October 2000. The site of observation is indicated on Fig. 4.

from the 14th in the afternoon till the end of the 15th (with a peak of $40 \mathrm{~mm} / 6 \mathrm{~h}$ on the 15 th in the morning) (BWG, 2002). No negative temperatures were recorded at $2500 \mathrm{~m}$ asl before the night of 16 to 17 October (cf. Fig. 4). Many streams suffered from debris flows and bed load events. Most of the dramatic cases occurred in the eastern part of Valais where exceptional precipitations were rather recorded on 13 and 14 October. In the western part, the most significant one, with a volume of about $15000 \mathrm{~m}^{3}$, seems to have been the debris flow in the St-Jean torrent, near Martigny, that occurred on 15 October in the morning. Its starting zones were situated between 1800-2000 m asl on a north aspect slope: they were affected by freezing conditions during the week prior to the triggering of the event (cf. Sect. 2.2).

Near $2000 \mathrm{~m}$ asl (Fig. 3), ice needles (also called pipkrakes) were observed on 8 October 2000 (see Fig. 4 for location), one week before the rainfall event. Their formation accompanied rapid decrease in air temperature that occurred from 6 October and was accompanied by two nights of clear sky permitting the ground surface to cool rapidly. According to snow conditions and air temperature, ice needles were likely to form especially between about 1500 (perhaps lower) and $2500 \mathrm{~m}$ asl at that time (own observation).

\subsection{Possible mechanisms}

\subsubsection{Modification of soil structure by pipkrakes}

We suggest the possibility that compression resulting from the increase in volume of water at the time of its 


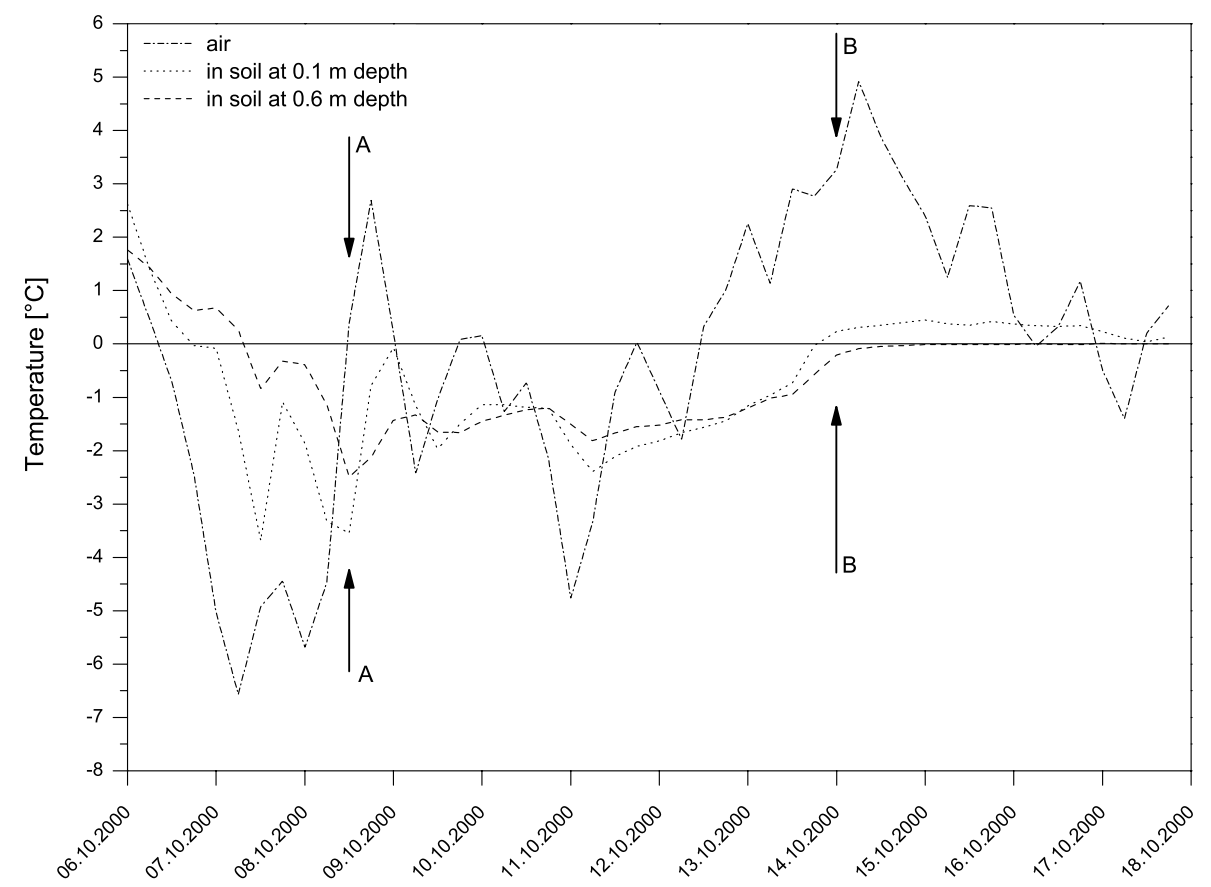

Fig. 4. Evolution of the temperature during the beginning of October 2000 in the air and at depth of 0.1 and $0.6 \mathrm{~m}$ in a borehole located at $2500 \mathrm{~m}$ asl, $17 \mathrm{~km}$ south-east from the site where ice-needles were observed. A is the date when the picture (Fig. 3) was taken and B is the start of most of the catastrophes.

transformation into ice, soil aggregates (here taken as a regolith or a young pedological formation as often found on alpine talus slopes) can be redistributed during the freezing process. Moreover the aggregates are ruptured when the water trapped in the microporosity of the latter starts to freeze and also while the pipkrakes are growing (Gatto et al., 2001). In this frozen state, the ground still conserves a certain degree of cohesion due to the ice cementing the particles, but aggregates and pieces of aggregates are redistributed (mainly towards the surface). Once the ice thaws, if such formations were not covered by snow, erosion rates can increase significantly (Haupts, 1967). The rate of erosion increases at the time of the beginning of the runoff because of the exposure of loose pieces of aggregates laying on the surface. Thereafter, a decrease occurs once the stock of removable soil particles is exhausted (Abrahams et al., 1995). The increase of fine particles in runoff thus enhances the propensity for coarser sediment to be entrained by runoff and later form debris flow.

The increase in erosion potential of the ground surface is particularly pronounced when freezing has only recently taken place (Van Klaveren and McCool, 1998), which was the case at the beginning of autumn 2000. It was also wet (30 $\mathrm{mm}$ of precipitation had already fallen between 1 and 5 October 2000). One can suppose that the quantity of easily removable material is dependent on the strength of the ice needles. The temperature curves of Fig. 5 show that this early frost was particularly intense, inducing a significant temperature gradient in the ground, which, as a consequence on the wet ground, supported the formation of ice needles (Coutard et al., 1988). The observation of ice needles in different sites and the favourable conditions for their formation seems to show that they probably developed throughout most of the zone affected by the extreme weather event, at an elevation of between approximately $1500 \mathrm{~m}$ asl and $2200-2400 \mathrm{~m}$ asl (snow line). This is the fringe where most of the debris flows started during this period. As a consequence, one can suppose that diffuse erosion was favoured at that time.

\subsubsection{Frozen layer beneath the ground surface}

The analysis of the subsurface ground temperature in a borehole drilled in the Lapires talus slope $(2500 \mathrm{~m}$ asl, northeastern oriented) shows, despite the presence of snow cover since 9 October, that the ground froze deeply (to at least $0.6 \mathrm{~m}$ depth) during the week preceding the rainfall event which began on 13 October 2000 (Fig. 4). During the period of precipitation, the temperature never rose above $0^{\circ} \mathrm{C}$ at a depth of $0.6 \mathrm{~m}$. This indicates that in depth the ground remained frozen during the whole event.

Infiltration being strongly reduced by the frozen state of the ground (Gatto et al., 2001), runoff was concentrated at the surface during at least the first part of the precipitation period. Consequently, jointly with the effects of the ice needles on the soil erosion, the quantity of sediment mobilized may have been larger than for an identical precipitation fallen on unfrozen ground. 


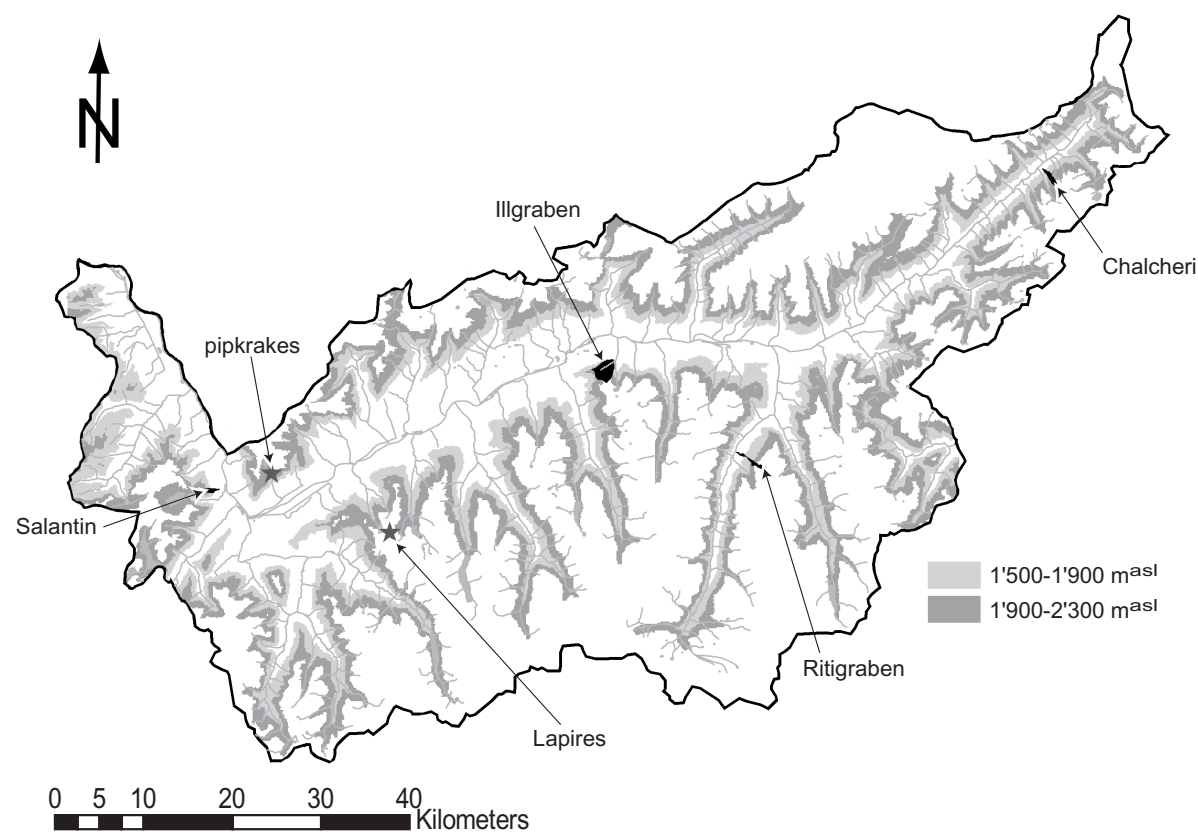

Fig. 5. Location of the four catchments investigated. See Fig. 2 for regional localization of the area.

\subsection{Discussion}

Four catchments, were analyzed in more detail to assess the relative effects of the amplification of erosion consecutive to the soil destructuring by ice needles and a runoff increase caused by the frozen state of the sub-surface ground reducing the water infiltration rate. For each case, the hypsometric curve of the basin was calculated. On these curves, the altitude section where the torrent crosses zones of easily removable material (determined by direct field observation) was mapped (thick line in Fig. 6). It is important to note that, due to cold air temperatures - particularly on 7, 8 and 11 October - and to the absence of snow cover beneath 2200-2400 m asl, relatively deep ground freezing (about $0.1-1 \mathrm{~m}$ ) was efficient until at least as low as $2000 \mathrm{~m}$ asl, and even lower in shadowed locations.

- The Illgraben stream is generally very active (Bardou et al., 2003) and we expected it to react strongly to the meteorological conditions. The zones potentially affected by pipkrakes formation and ground freezing did not practically affect the production areas of the torrent, which could explain the weaker than that expected response.

- The gully of Chalcheri is a small gully with an ephemeral stream. It produced a large debris flow leaving deposit more than $1 \mathrm{~m}$ thick during the October 2000 event. The entire zone where sediments were easily available is located at elevations where ground freezing processes were active during the preceding week, possibly amplifying the erosion of the ground surface and, hence, the debris-flow size.
- Salantin produced a debris flow in a gully which was not known for this kind of event, but rather for snow avalanches. The low elevation of the zone where there was removable material seems to indicate that, in this case, only the extreme quantities of rain are at cause.

- The Ritigraben torrent has a peculiar characteristic in the sense that two triggering zones exist. The principal one developed between 2400 and $2600 \mathrm{~m}$ asl in a sector collecting the water infiltrated in the uppermost periglacial (permafrost) area of the slope (2600$3000 \mathrm{~m}$ asl). The second zone of erosion lies below $1360 \mathrm{~m}$ asl. Ritigraben is prone for debris flows and during the last 15 years, major events easily reach $15000 \mathrm{~m}^{3}$ and more of deposited material. In October 2000 , no debris flow was triggered from the upper zone. Only $2500 \mathrm{~m}^{3}$ of materials apparently coming from the lower erosion section reached the road crossing the torrent channel at the foot of the slope. It can be assumed that the major triggering zone was previously covered by snow (as well as the upper collecting zone). This certainly did not avoid the deep freezing of the ground (the snow cover was generally not thick enough to completely insulate the blocky ground surface from an intense cooling) but prevented the growth of pipkrakes on fine soil portions. All these processes, combined to the probable low rate of infiltration in the upper collecting zone (frozen ground and precipitation mostly as snow), did not conduct to the triggering of a debris flow in the upper section of the Ritigraben. The only inferior triggering zone underwent significant erosion (explaining the low magnitude of the debris flow event on the lower road). 

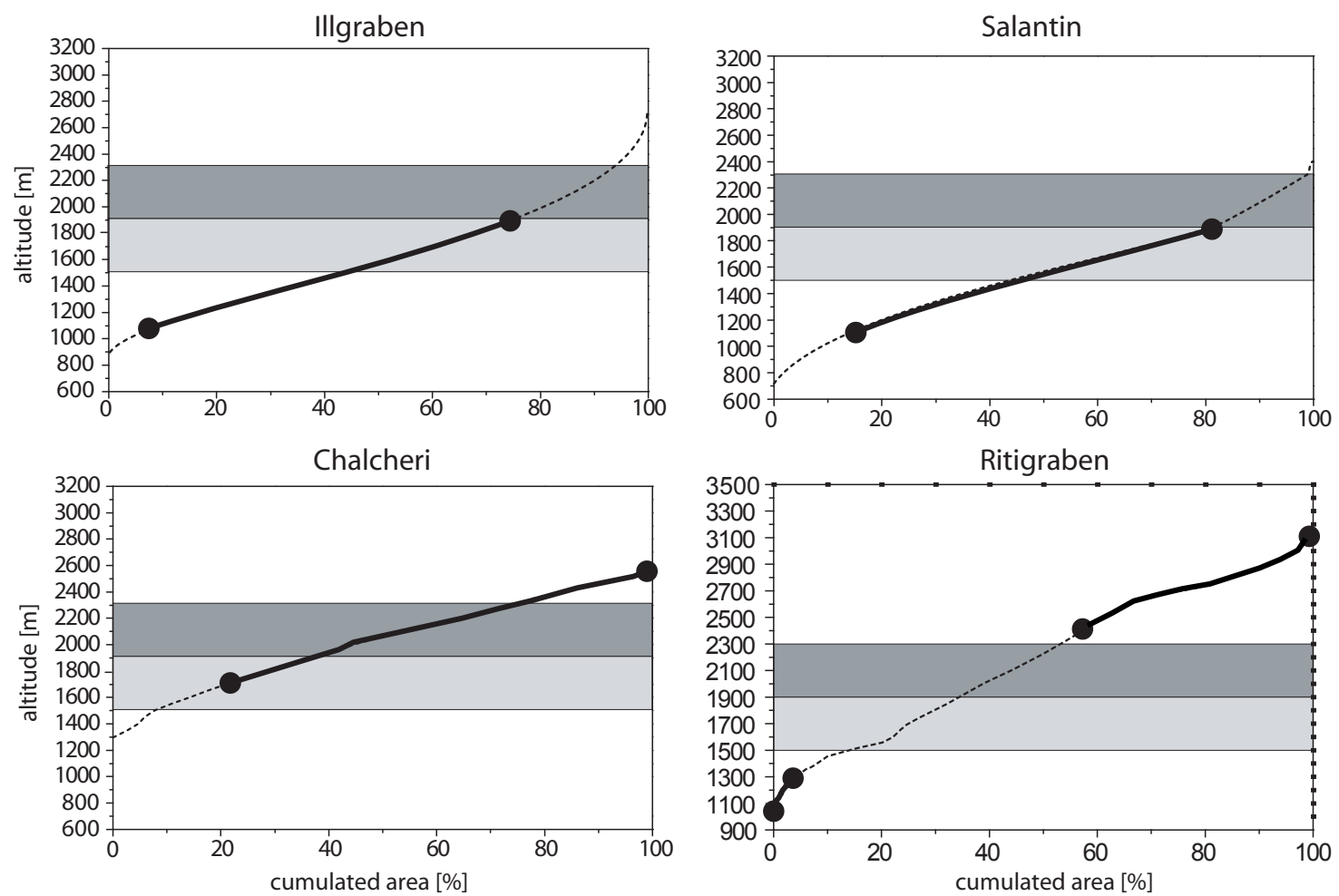

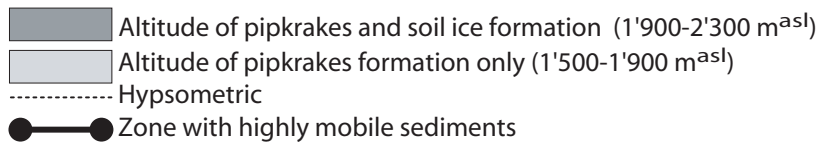

Fig. 6. Hypsometrical curves for 4 catchments with temperature bands where the different reported mechanisms occurred and the location where there is abundant material available for entrainment (heavy black line).

The analysis of the debris flows linked to the extreme weather event in October 2000 indicates that the phenomena of freezing-thawing related to the previous moisture of the ground and to the evolution of both air and ground temperatures before the event could amplify or prevent the erosion phenomena depending on elevation. Field observations were not sufficient to determine if this factor only is responsible for triggering certain debris flows. Indeed, the weather conditions during the period were extreme and many debris flows would have surely occurred even without the previous intense freeze/thaw cycles occurring within the surface and uppermost layers of the ground. However the relationship between thawing conditions in the ground and precipitation had already been indexed as a critical condition for the triggering of debris flows (Church and Miles, 1987).

For the low altitude catchments (especially in the western part of the studied area, cf. also Sect. 4), the influence of the freezing-thawing process can be considered as negligible as the air temperature remained higher than $0^{\circ} \mathrm{C}$ for the whole of the relatively cold week preceding the bad weather event.

\section{The "preparing effect" of the avalanches}

The quantities of water necessary to form debris flows come either from direct rainfall and underground (taken in a wide sense). The correspondence of some debris flow gullies and avalanche corridors and observations (during flow as well as in the triggering zone) let us think that there is a link between the two phenomena.

\subsection{Observations}

During winter 1998/99 several major avalanches occurred in the ECA. During the two following summers, great quantities of snow deposits were observed even at low altitude (cf. Fig. 7). Meanwhile, ten monitored streams showed an upsurge in debris flow activity. That pushed us to investigate the role played by the avalanches in the generation of sediment - laden flow.

Several observations of flow containing a significant quantity of sediment were made in clear weather in gullies known to be prone to debris flows (often during the hot and sunny days of July and August). Conjointly to these observations, the presence of avalanche deposit was evident on the bed of many gullies in the Valais Alps as exemplified in Fig. 8). 

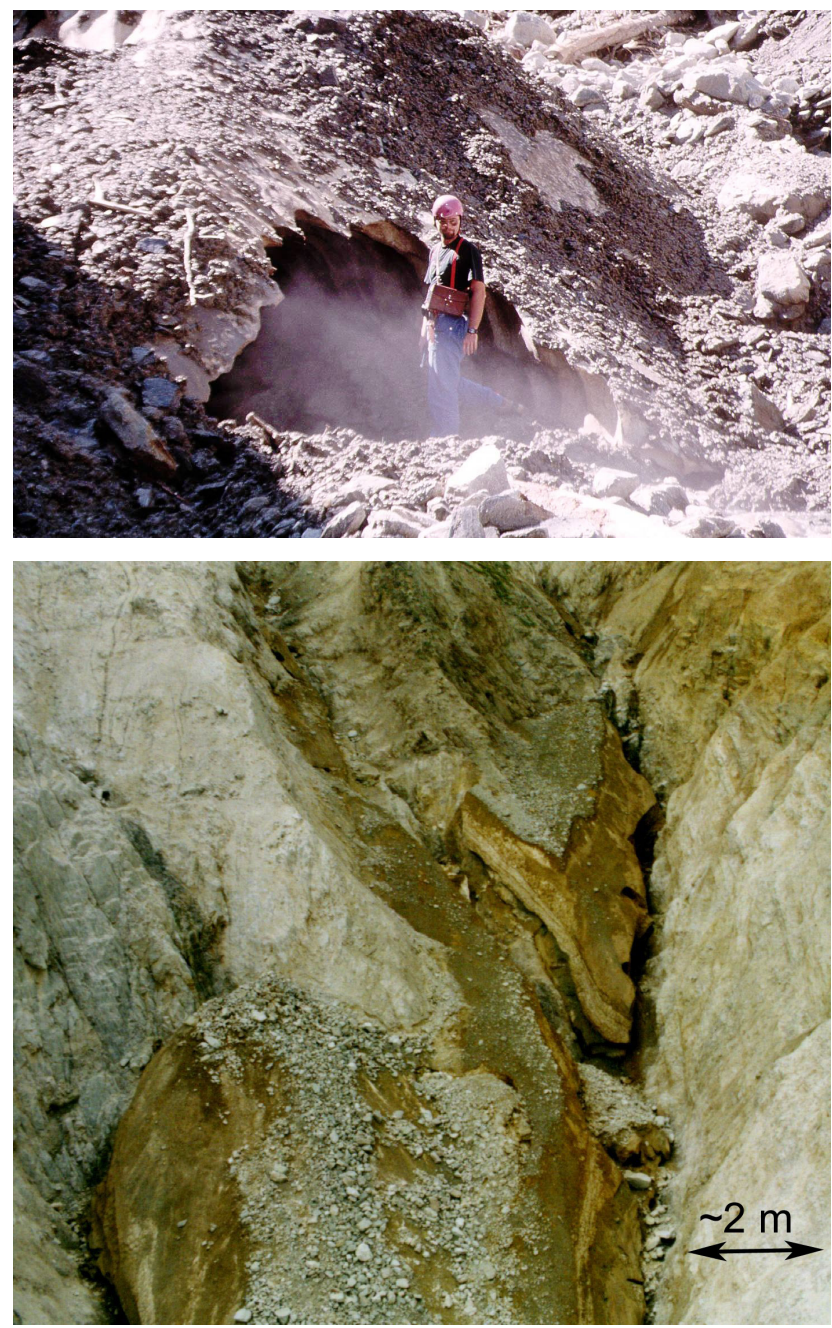

Fig. 7. (a) Snow covered by rocky debris deposited in the gully where debris flows are usually triggered (summer 1999); (b) Gully still mantled by avalanche deposits in summer 2000 (i.e. two summer after the fatal winter of 1999).

\subsection{Possible mechanism}

The role of these deposits could be twofold. First, the quantity of snow represents a non-flowing water storage during the winter. This water is released when the temperature increases and is added to the base flow. During rainfall (not necessarily intense) the runoff quantity could thus be enough to trigger a debris flow. Several authors described a similar situation when an intense temperature increase intervenes after a very wet spring (e.g. Baur et al., 1992).

Secondly, in the zones active geologically, the avalanche deposits are frequently covered by sediments during the following spring. As the summer rise in temperatures, the upper zone of the subjacent snow deposits softens, forming a very efficient sliding plane for the sediments. These small slips contribute to fill gullies with highly mobile sediment (cf. Fig. 9). It is reasonable to suppose that consequent debris flows can result simply from the alternation of melting and these sedimentary contributions (cf. Fig. 1).

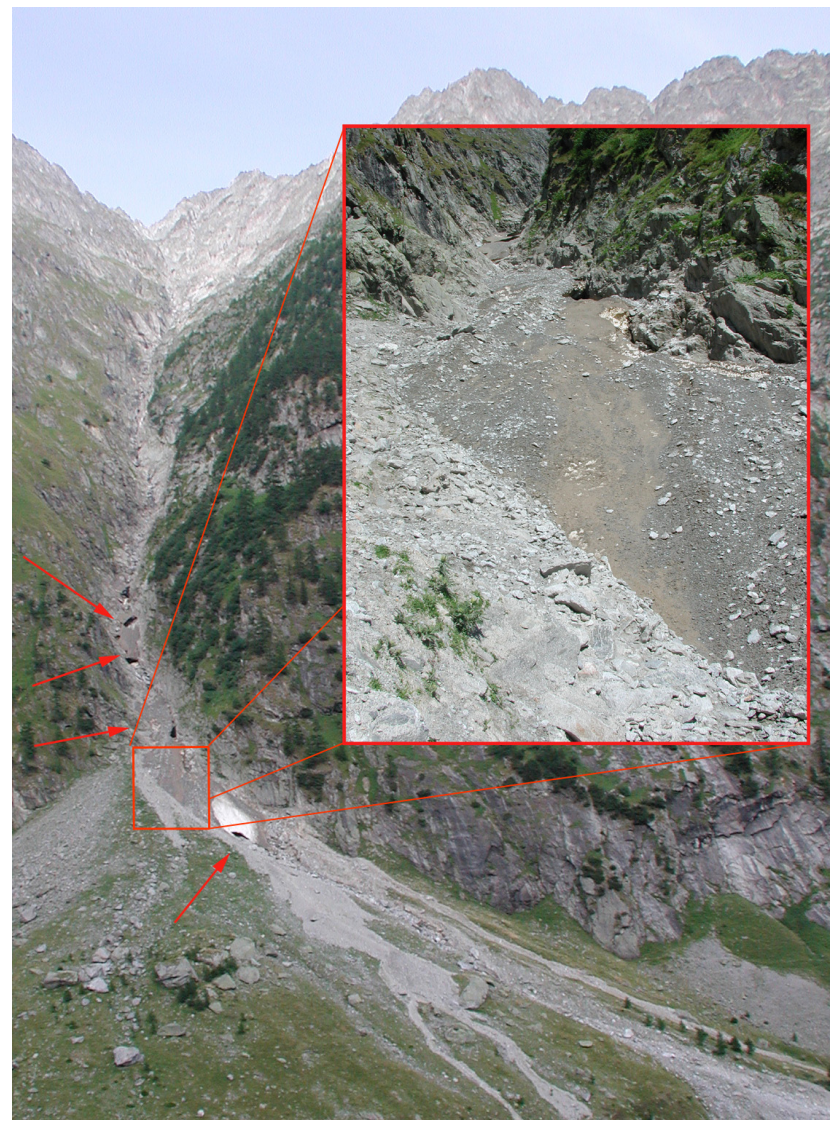

Fig. 8. During the particularly hot summer 2003 (e.g. Schär et al., 2004), a gully in the Baltschieder valley after a debris flow triggered by rainfall: note the bed covered by snow avalanche deposit (courtesy of M. Sartori).

\subsection{Discussion}

In order to evaluate the effect of the avalanches on triggering debris flows, we tried to characterize the avalanche activity level of a given year and a given gully. For that two proxies were available. The first one, available over the period 19371987 consists with the analysis of the number of fatalities due to avalanches on roads and in buildings (corrected linearly to take account of protection work, mainly committed since the winter 1951-1952). Each year with more than 10 deaths is defined as a year of remarkable avalanche activity.

The second proxy which is more precise spatially, has been available since 1987. It uses the danger level used in the $\mathrm{Na}$ tional avalanche bulletin (it thus truly qualifies the avalanche activity). When more than 2 days are classified as danger level 5 (the maximum on the European danger scale), or more than 10 days are classified as danger level 4 , the year is classified as a year of remarkable activity. Information on the avalanche activity and that on the debris flows is not given with the same spatial resolution. The avalanche activity is estimated at a regional scale whereas the debris flows relate 

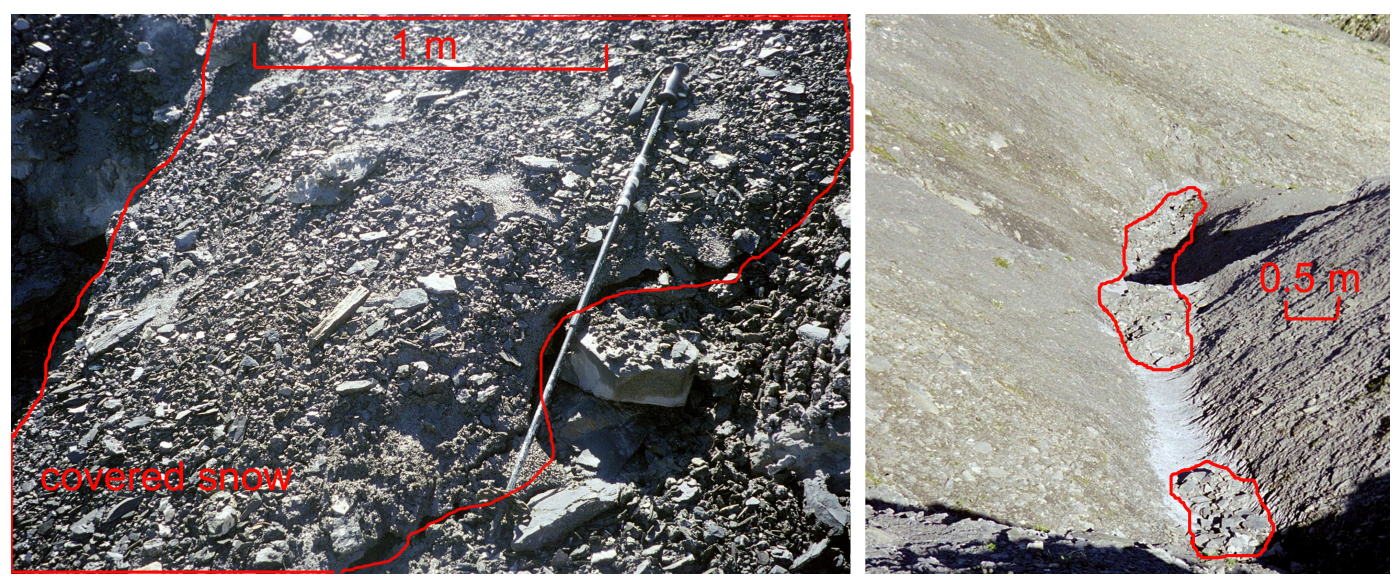

Fig. 9. Snow covered by debris and the consecutive small slided pack of debris prefiguring a debris flow that slide on snow deposit near the pass of La Croix de la Cha in summer 2003.

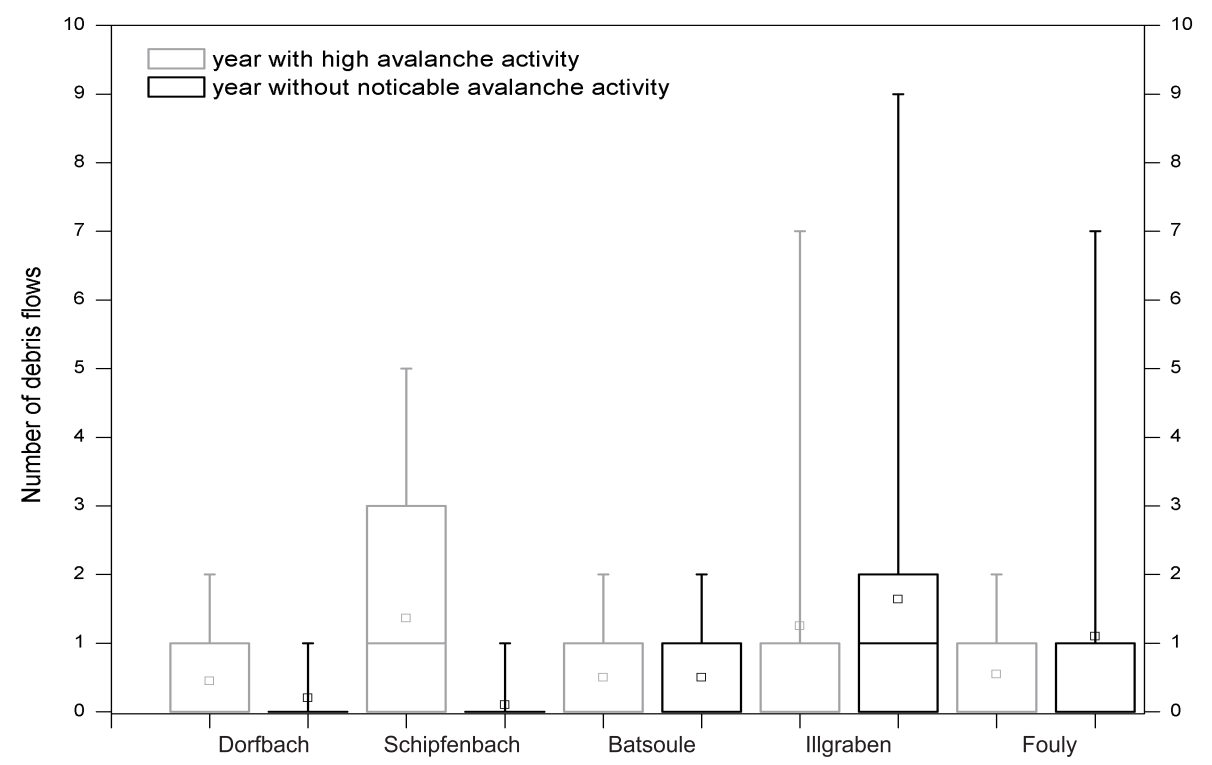

Fig. 10. Event distribution according to years with and without noticeable avalanche activity.

to a unique gully. However, due to the landscape disposition, the avalanche corridors match up with the gullies prone to debris flows. It is thus reasonable to think that the avalanche activity of the region applies to the selected gullies.

The years thus selected are compared with the records of debris-flow events available. As our field observations show, the deposits of major avalanches can be preserved at low altitude at least during the two consecutive summers (cf. Fig. 7). This is why we compared the avalanche activity with the number of debris flows which have occurred over a period of two years. To estimate the importance of this process, the same treatment was applied to the debris flows which occurred in the years considered as not having a strong avalanche activity.

Table 1 synthesizes that generally in winters with remarkable avalanche activity, the number of debris flows seem to be more significant during the two summers following a given winter. If we account this to the fact that the presence of avalanche deposits is an aggravating factor for the triggering of debris flows amongst others, the relationship is particularly obvious for the Dorfbach and Schipfenbach streams, and less marked for the Batsoule stream (cf. Fig. 10).

Apparently the result is reversed for the Illgraben and Fouly streams. The detailed analysis of the events, which have occurred in these two torrents, indicates that other preparatory and/or amplifying phenomena can completely mask the effect of the avalanches alone. In the case of the Illgraben stream, a Bergsturtz $\left(5 \times 10^{6} \mathrm{~m}^{3}\right)$ filled the valley over more than $1 \mathrm{~km}$ forming a huge natural dam. The latter broke in June 1961. It is reasonable to think that the 15 debris flows, which occurred during the 3 following years, are the consequence of this availability of material (own observations). 
Table 1. Mean debris flow numbers over two consecutive summers for year with and without noticeable avalanche activity.

\begin{tabular}{llllll}
\hline & Dorfbach & Schipfenbach & Batsoule & Illgraben & Fouly \\
\hline year with high avalanche activity & 0.44 & 1.67 & 0.56 & 1.25 & 0.56 \\
year without noticeable avalanche activity & 0.20 & 0.11 & 0.56 & 1.89 & 1.57 \\
\hline
\end{tabular}

In the case of the Fouly stream, one can see that in fact it is the events which occurred in 1987 that influence the mean (cf. Table 1). The historical chronicles tell us that during this summer, rainfall was particularly intense all over Europe (Guzzetti et al., 1992; Rickenmann and Zimmermann, 1993). It seems plausible that over the summer of 1987 rains deeply destabilized the gullies, which in turn predisposed the gullies to lead to the 7 consecutive events. One can suppose again that the availability of sediment masks the preparatory effect of the avalanches.

One shortcoming of this approach is the fact that debris flow triggering is a very complex phenomenon driven by in situ material properties, water storage in the ground, quantity of rainfall, temperature, etc. It could not be said from our data which combination of the above processes is responsible for the triggering of one precise debris flow, but our results show a trend that should be investigated.

It should be noted that the summer immediately following a winter with remarkable avalanche activity generally does not experience any, or little, debris flow events. This could be attributed to the fact that these deposits of very dense snow form an effective protection for the gully bed (cf. Sect. 4.1) and/or that the sedimentary refill which occurs in spring forms a mass of highly mobile sediment (e.g. at the time of the freeze-thaw periods).

\section{The limiting effect of avalanches}

Unlike the above presented process, the snow cover could obviously act as a shield against the rainfall. This protecting effect could in turn limit the triggering of sediment transfer in alpine torrents.

\subsection{Observations}

During a period of warmer temperatures in January 2004, rain fell at high altitude onto a snow-covered territory. Several events implying sediment took place. Again the interest of the analysis lies in the comparison between the sedimentary responses of different streams. More precisely, on monitored streams which did not react as expected.

Before the rainfall the snow cover extended down to about 1000-1200 m asl. Then during the event, warm air masses and rainfalls made the snow disappear below about 1900$2000 \mathrm{~m}$ asl (depending on the slope aspect). However, in avalanche corridors, the snow deposits could be found locally down to about 1200-1500 m asl. The map in Fig. 11

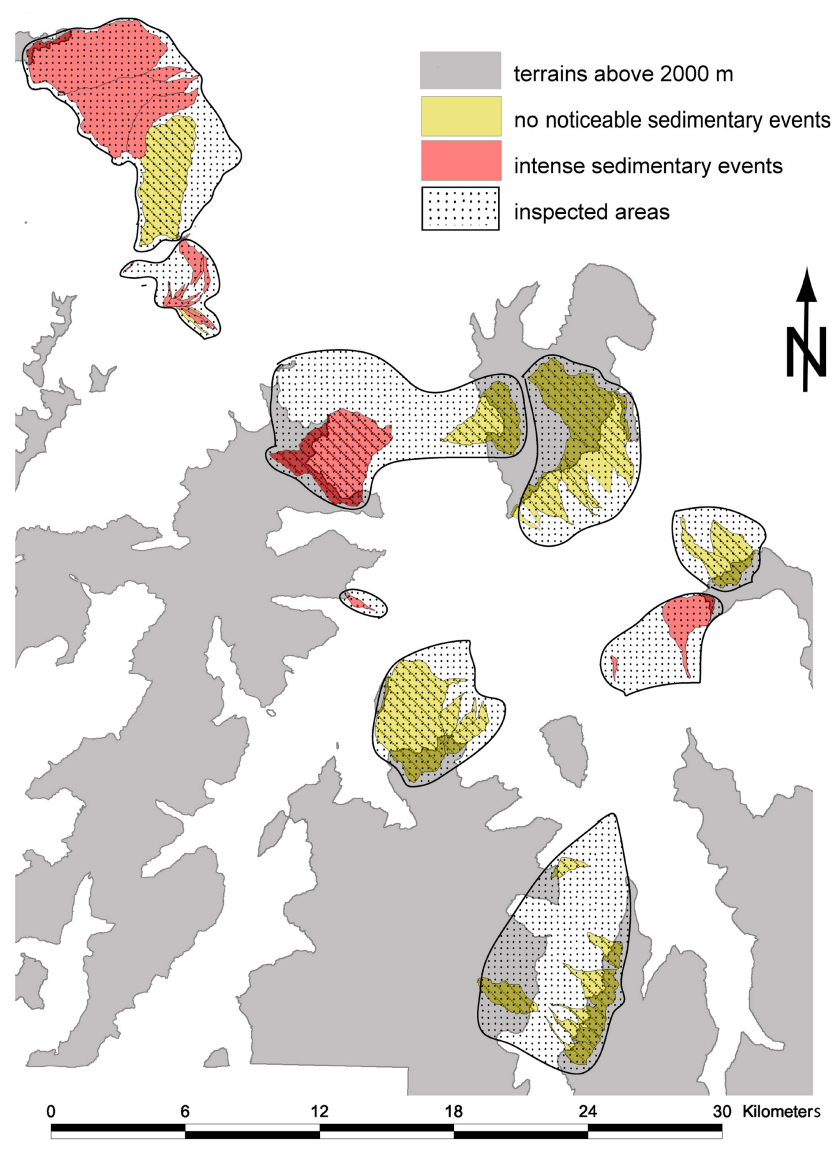

Fig. 11. Area surveyed during the meteorological event of 14 January 2004 with indication of the maximal elevation where the snow cover completely melted and the type of catchment reactions. Cf. Fig. 2 for regional localization.

qualitatively shows the spatial relationship between the maximal elevation where the snow cover completely melted (set at $2000 \mathrm{~m}$ asl) and the catchments surveyed.

\subsection{Possible mechanisms}

The following mechanisms can be suspected in presence of a snow cover. Firstly, the effect of the direct impact of the raindrops, the splash effect which makes particles capable of being detached, is completely annihilated (Gatto et al., 2001). Secondly, the additional normal stress (unit weight of snow is between 500 and $600 \mathrm{~kg} / \mathrm{m}^{3}$ ) increases the cohesion of the sediments thus protecting them from the effect of the runoff which appears at the bed-deposit interface. 


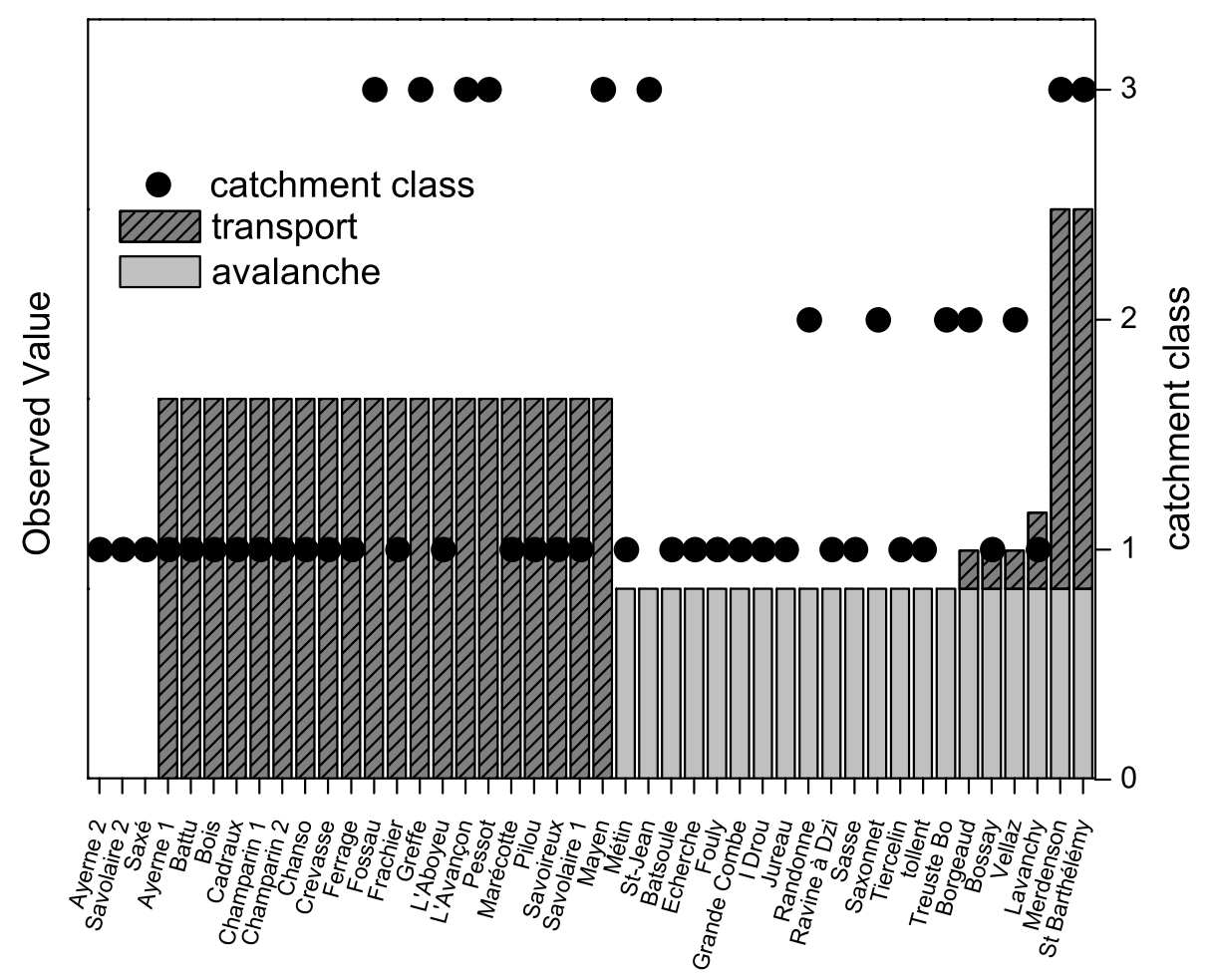

Fig. 12. Analysis of the sedimentary reaction of some gullies with respect to the presence of avalanche deposits. Observed values are qualitative (i.e. the relative size of the bars on the graphs). They mean "presence/absence" for avalanches and "no/very little/intense activity" for sediment transfer. The catchment class is defined on the basis of the surface area and Strahler's order.

\subsection{Discussion}

The state of the gully was observed during the events and any traces of sedimentary activity (debris flows or bed load) were noted. When the starting zones (globally known as a preliminary) were not visible from the outlet of the system, additional visits were carried out. Figure 11 depicts the extent of this survey. The observations showed that the streams which had no or a weak response than the one expected (i.e. a mild sedimentary activity) had the upper part of their basin (therefore a part of their starting zones) coated with deposits of wet snow (thus of very dense snow). The map of Fig. 11 shows that a majority of catchments with a consequent part of their reception surface above $2000 \mathrm{~m}$ asl reacted little. The catchments in zones of lower altitudes had a more intense sedimentary reaction. This could be linked with the increase in their base flow due to a fast melting of the snow cover and the lack of protection of their gullies by avalanche deposits. Moreover, below the surface, the ground could have been frozen at some places in the catchments (especially where snow was thin or lacking prior to the rainfall episode) what in turn, at least temporarily, could have increased the surface runoff (cf. Sect. 2.1).

The graphs on the Fig. 12 show that in the majority of the cases, the intensity of the sedimentary response is influenced by the presence of avalanche deposits. As for other observations concerning natural phenomena, some exceptions remain. For the two obvious ones, the Merdenson and St-
Barthelemy streams, where an intense sedimentary activity was concomitant with avalanche deposits (on the right of the graph on Fig. 12), the following explanation can be given.

Sedimentary activity in mountain watersheds is a complex geomorphological system that implies either the drainage basin and/or channel processes. Thus, mountain watershed could be subdivided into many subsystems accounting for erosion or storage of sediments. It appeared that basin comparisons from downstream do not guarantee a good characterization of the whole system (Bogen, 1995). To allow adequate comparisons, we worked out a catchment classification function of their size and of their hydrological behaviour (Stahler's order is used as a proxy). On this basis one can see that the two exceptions are of order 3 (either $>3 \mathrm{~km}^{2}$ and/or Strahler's order $>3$ ). The complex system formed by such basins lets suppose that the transfer of sediment can occur in the subsystem, downstream of the upper starting zones influenced by snow.

\section{General discussion}

The altitude of the snowfall limit during a precipitation episode plays a major role on the debris-flow activity. Nevertheless, other climatic-physical processes related to the phase of water (solid or liquid) appears to have an influence on the triggering of debris flows in particular and on the transfer of sediment in general. The presence of snow covering 
the ground surface, the previous destructuration of the soil caused by freezing (e.g. pipkrakes growth), the decrease in infiltration rate consecutive to the frozen state of the ground or the ambivalent effect of (late-laying) snow avalanche deposits accumulated in gullies are factors that can modulate during one single precipitation episode, the quantity of water and loose sediments available for the formation of debris flows. Snow cover, avalanche deposits and water frozen within the ground can also be considered as storage of precipitation (generally over a few days, but up to a number of years) that may affect water supply, which increases the base flow.

These phenomena located at or near the soil surface may be responsible, sometimes in a dominating way, for the mobilization of sediments. However, the impact of raindrops and the runoff (due only to rainfall) can already set sediments moving. This is why the results of the observations presented here only show a tendency. The quantitative importance of the amplifying (or protecting) effect of the involved factors is difficult to evaluate. These effects are perhaps entirely responsible for some debris flow (non-)events and they are to be blamed, as an additional factor, in a more significant number of (non-)events. If it is difficult to currently give a threshold for forecasts, the knowledge of these potential triggering mechanisms can already be integrated with benefit into a watershed monitoring system. Furthermore, previous survey and analysis of the catchment functioning (e.g. with hypsometrical curves) could be a valuable tool to inspect the potentiality of debris flow outbreak.

In addition to the uncertain measurement of these mechanisms which are sometime diffuse, some difficulties were encountered with the data-collection. Among others, the survey of a vast region having undergone an extreme weather event is relatively badly formalized in the point of view of the "lesson(s) learned". The attention generally goes to the most serious cases, omitting the evidence coming from gullies and torrents which could have reacted, but where the traces are not well visible. On the only basis of the observations of streams having overflowed, it is very difficult to make comparisons in time helpful for a better understanding of debris flow initiation. Consequently, evaluating the effect of different factors on the characteristics of the sedimentary events is not obvious. This is what pushed us to differentiate the catchments into several classes (cf. Sect. 4.2). This classification, still in development and tested here for the first time, allows to perform more effective comparisons ensuring that they are statistically representative.

The classification of the catchments, as well as an adequate methodology of regional surveys when extreme weather episodes are occurring (e.g. cartographic differentiation between the unsurveyed zones and surveyed zones but without visible phenomenon) are tracks to follow in the future. This could help to improve the data acquisition relating to this kind of events.

If the climatic-physical processes described in this paper are not the cause of the majority of events, they may directly or indirectly influence the triggering of a considerable part of debris flows. However, these processes, related to slope deposits, are little known (Caballero et al., 2002). A better understanding would make it possible to improve the forecasting of mass movement events. Moreover, if further measurements could be done to better specify the influence of these processes, our monitoring capabilities will be enhanced.

Acknowledgements. We want to thank S. H. Cannon and V. Jomelli for interesting comments and fruitful discussion. We want also to thank F. Dufour (SLF) for helping us with the avalanche data.

Edited by: G. B. Crosta

Reviewed by: V. Jomelli and S. H. Cannon

\section{References}

Abrahams, A. D., Parsons, A. J., and Wainwright, J.: Effects of vegetation change on interrill runoff and erosion, Walnut Gulch, southern Arizona, Geomorph., 13, 37-48, 1995.

Anderson, S. A. and Sitar, N.: Analysis of rainfall induced debrisflow, J. Geotech. and Geoenvir. Engrg. , 121(7), 544-552, 1995.

Bardou, E., Fournier, F., and Sartori, M. Paleofloods reconstruction on Illgraben torrent (Switzerland): a need for today frequency estimation, International Workshop on Paleofloods, Historical Data \& Climatic Variability: Applications in Flood Risk Assessment, Barcelona, 2003.

Barry, R. G.: Mountain, weather and climate, Routledge, London, 1992.

Baur, M., Edmaier, B., and Spaun, G.: Talzuschübe als geschiebeherde für Murgangeriegnisse in Saalbach und Rauris (Land Salzburg), in: F.f.v. Hochwasserbekämpfung (ed), International Symposium Interpraevent, Birkäuser Verlag, Bern, 165-180, 1992.

Bogen, J.: Sediment transport and deposition in mountain rivers, in Sediment and water quality in river catchment, edited by Foster, I., Gurnell, A. and Webb, B., John Wiley \& Sons, Chisester, 437451, 1995.

BWG (Federal Office for Water and Geology): Hochwasser 2000Les crues 2000, Berichte des BWG, Serie Wasser Nr.2, BWG, Bern (in German), 2002.

Caballero, Y., Jomelli, V., Chevallier, P., and Ribstein, P.: Hydrological characteristics of slope deposits in high tropical mountains (Cordillera Real, Bolivia), CATENA, 47, 101-116, 2002.

Cannon, S. H., Kirkham, R. M., and Parise, M.: Wildfire-related debris-flow initiation processes, Storm King Mountain, Colorado, Geomorph., 39, 171-188, 2001.

Church, M. and Miles, M. J.: Meteorological antecedents to debris flow in southwestern British Columbia, in: Debris flow \& avalanche: process recognition and mitigation, Wieczorek, G. F. and Costa, J. E. (eds), Reviews in engineering geology, Geol. Soc. Am., Boulder, 63-79, 1987.

Coutard, J.-P., Van Vliet-Lanoe, B., and Auzet, A.-V.: Frost heaving and frost creep on an experimental slope: results for soil structures and stored stripes, Z. f. Geomorph., 71, 13-23, 1988.

Ellen, S. D. and Fleming, R. W.: Mobilization of debris flows from soil slips, San Franscico Bay region, California, in: Debris flow $\&$ avalanche: process recognition and mitigation, Wieczorek, G. F. and Costa, J. E. (eds), Reviews in engineering geology, Geol. Soc. Am., Boulder, 31-40, 1987.

Fazel, A.: Nevado del Ruiz, Colombia: Volcanic Hazards, Brooke University, Brooke, 1991. 
Gatto, L. W., Halvorson, J. J., McCool, D. K., and Palazzo, A. J.: Effetcts of freeze-thaw cycling on soil erosion, in: Landscape Erosion and Evolution Modeling, Harmon, R. S. and Doe, W. W. (eds), Kluwer Academic/Plenum Publishers, New York., 2001.

Gomez, B., Russell, A. J., Smith, L. C., and Knudsen, Ó: Erosion and deposition un the proglacial zone, the 1996 jökulhlaup on Skeidarársandur, southeast Iceland, The extrems of the extremes: Extraordinary Floods, IAHS, Reykjavik, 217-221, 2002.

Gostner, W., Bezzola, G. R., Schatzmann, M., and Minor, H. E.: Integral analysis of debris flow in an Alpine torrent - the case study of Tschengls, in: Rickenmann, D. and Cheng-lung, C. (eds), 3rd Int. Conf. on Debris-Flow Hazards Mitigation, Mechanics, Prediction and Assessment, Davos, 2003.

Grebner, D.: Meteorologische Analyse des Unwetters von Brig und Saas Almagell vom 24. September 1993, Wasser, Energie, Luft, 86(1/2), 41-44 (in German), 1994.

Guzzetti, F., Crosta, G., and Marchetti, M.: Debris flows triggerred by the July 17-19 storm in the Valtellina area (Northern Italy), in: F.f.v. Hochwasserbekämpfung (ed), International Symposium Interpraevent, Bern, 193-204, 1992.

Haeberli, W., Kääb, A., Vonder Mühll, D., and Teysseire, P.: Prevention of outburst floods from periglacial lakes at Gruben Glacier, Valais, Swiss Alps, J. Glaciol., 47 (156), 111-122, 2001.

Haupt, H. F.: Infiltration, overland flow, and soil movement on frozen and snow-covered plots, Water Resource Research, 3(1), 145-161, 1967.

Huggel, C., Kääb, A., Haeberli, W., and Krummenacher, B.: Regional-scale GIS-models for assessment of hazards from glacier lake outbursts: evaluation and application in the Swiss Alps, Nat. Haz. Earth Sys. Sci., 3, 647-662, 2003, SRef-ID: 1684-9981/nhess/2003-3-647.

Hungr, O., Morgan, G. C., and Kellerhals, R.: Quantitative analysis of debris torrent hazards for design of remedial measures, Canadian Geotechnical Journal, 21, 663-677, 1984.

Jakob, M., Hungr, O., and Thomson, B.: Two debris flow with anomalously high magnitude, in: 1st International Conference on Debris-Flow Hazards Mitigation, Mechanics, Prediction and Assessment, edited by Chen, C.-L., ASCE, San Fransico, 382394, 1997.

Jishan, W. and Tianchi, L.: Behaviour and charcteristics of debris flows, in: Tianchi, L., Chalise, S. R., and Upreti, B. N. (eds), Landslide Hazard Mitigation, ICIMOD, Kathmandu, 2001.

Kääb, A., Wessels, R., Haeberli, W., Huggel, C., Kargel, J. S. Khalsa, S. J. S.: Rapid Aster imaging facilitates timely assessments of glacier hazards and disasters, EOS 13/84: 117, 121, 2003

Klubertanz, G., Laloui, L., and Vulliet, L.: Parameters governing debris flow initiation, in: Wieczorek, G. F. and Naeser, N. D. (ed), 2nd Int. Conf. on Debris-Flow Hazards Mitigation, Mechanics, Prediction and Assessment, Balkema, Taipei, 2000.

Lugon, R., Gardaz, J.-M., and von der Mühll, D.: The partial collapse of the Dolent glacier moraine (Mont Blanc Range, Swiss Alps), Z. f. Geomorph., 122, 191-203, 2000.
Meunier, M.: Eléments d'Hydraulique torrentielle, CEMAGREF, Grenoble, 1991.

Montgomery, D. R., Dietrich, W. E., Torres, R., Anderson, S. P., Heffner, J. T., and Loague, K.: Hydrologic response of a steep, unchanneled valley to natural and applied rainfall, Water Resources Research, 33, 1, 91-109, 1997.

Mool, P. K., Bajracharya, S. R., and Joshi, S. P.: Inventory of Glaciers, Glacial Lakes and Glacial Lake Outburst Floods, ICIMOD, Kathmandu, 2001.

OFEE (Federal Office for Water Ressources): Analyse des causes des crues de l'année 1987, final report. (in french), 1991.

Plafker, G. E., Ericksen, G. E., and Fernandez Concha, J.: Geological Aspects of the May 31, 1970, Peru Earthquake, Bull. Seism. Soc. Am., Vol. 61, 3, 543-578, 1971.

Reynolds, J. M.: The identification and mitigation of glacier-related hazards: examples from the Cordillera Blanca, Peru, in: Geohazards natural and man-made, McCall, G. J. H., Laming, D. J. C. and Scott, S. C. (eds), Chapman and Hall, London, 143-157, 1992.

Rickenmann, D. and Zimmermann, M.: The 1987 debris flows in Switzerland: documentation and analysis, Geomorph., 8, 175189, 1993.

Schär, C., Vidale, P. L., Lüthi, D., Frei, C., Häberli, C., Liniger, M. A., and Appenzeller, C.: The role of increasing temperature variability in European summer heatwaves, Nature, 427, 332336, 2004.

Springman, S. and Teysseire, P.: Artificially induced rainfall instabilities on moraine slopes, in: Kühne, M., Einstein, H. H., Krauter, E., Klapperich, H., and Pöttler (eds), Int. Conf. on Landslides, Causes, Impacts and Countermeasures, Davos, R., Verlag Glückauf Essen, 209-223, 2001.

Tropeano, D., Luino, F., and Turconi, L.: Evento alluvionale del 14-15 ottobre nell'Italia Nord-Occidentali, Fenomeni ed effeti, Territorio e difesa del suolo GEAM(12), 203-216, 2000.

Van Klaveren, R. W. and McCool, D. K.: Erodibility and critical shear of a previously frozen soil, Trans. Am. Soc. Agric. Engrg, 41, 1315-1321, 1998.

Waitt, R.B. Jr., Pierson T. C., MacLeod N. S., Janda R. J., Voigt B., Holcomb R. T.: Eruption-triggered avalanche, flood and lahar at Mount St. Helens - effects of winter snowpack, Science, 221, 1394-1397, 1983.

Wei, W. and Gao, C.: Studies of ice-snow melt debris flows in the western Tian shan Mountains, China, in Erosion, Debris Flows and Environment in Mountain Regions, IAHS Publ., 209, Chengdu, 329-336, 1992.

Zimmermann, M.: Debris flows 1987 in Switzerland: geomorphological and meteorological aspects, in: Hydrology in mountainous regions II: artificial reservoirs, water and slopes, edited by Sinniger, R. O. and Monbaron, M., IAHS, Lausanne, 387-393, 1990.

Zimmermann, M., Mani, P., Gamma, P., et al.: Murganggefahr und Klimaänderung - ein GIS-basierter Ansatz, Schlussbericht NFP 31, vdf Hochschulverlag, Zürich, 1997. 